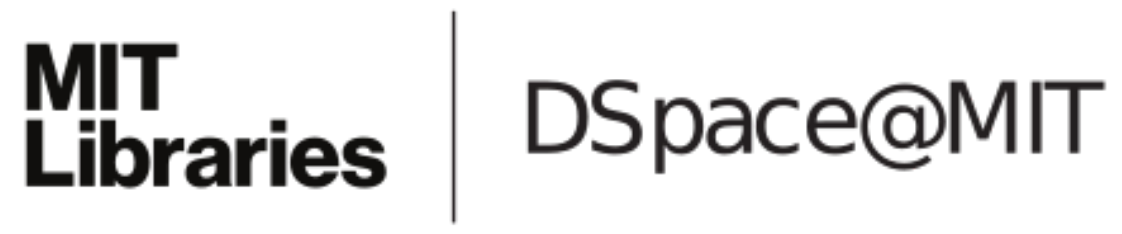

\author{
MIT Open Access Articles
}

Detecting the effect of under-correcting myopia

The MIT Faculty has made this article openly available. Please share how this access benefits you. Your story matters.

Citation: Medina, Antonio. “Detecting the Effect of under-Correcting Myopia." Graefe's Archive for Clinical and Experimental Ophthalmology 254.2 (2016): 409-410.

As Published: http://dx.doi.org/10.1007/s00417-015-3111-2

Publisher: Springer Berlin Heidelberg

Persistent URL: http://hdl.handle.net/1721.1/105363

Version: Author's final manuscript: final author's manuscript post peer review, without publisher's formatting or copy editing

Terms of Use: Article is made available in accordance with the publisher's policy and may be subject to US copyright law. Please refer to the publisher's site for terms of use. 


\title{
Detecting the effect of under-correcting myopia
}

\author{
Antonio Medina ${ }^{1,2}$ \\ Received: 2 July 2015 / Accepted: 18 July 2015 /Published online: 9 August 2015 \\ (C) Springer-Verlag Berlin Heidelberg 2015
}

Keywords Myopia $\cdot$ Under-correction $\cdot$ Myopia progression

\section{Dear Editor,}

The Letter to the Editor "Refractive correction and myopia progression" [1] ("the Letter") makes some good points about the article "The progression of corrected myopia" [2] that the article had already addressed in part.

Medina's feedback model for emmetropization predicts that correction of myopes aggravates their condition, and that delaying correction will result in less progression rate and probably a reduced myopic final level. The model also predicts that under-correcting myopia would have a small effect in reducing the progression rate.

The Letter advises that there is controversy on the issue of whether under-correction of myopia will have any beneficial effect, citing four published reports [3-6] involving distance under-correction. Medina [2] cites those reports, and others, noting the conflict and suggesting experimental problems. The Letter overlooks several reports that show that undercorrection for near vision with bifocals reduces myopia progression, e.g. [7] and those cited in [2].

In response to the Letter, the effect of distance undercorrection would be difficult to detect experimentally due to the small effect and the difficult experiment. Reports [3-6, 8]

Antonio Medina

puerta@alum.mit.edu

1 Massachusetts Institute of Technology, Research Laboratory of Electronics, Cambridge, Massachusetts 02139, USA

2 Present address: Multivision Research, 1590 Adams Ave 2355, Costa Mesa, CA 92628, USA discussed in the paragraphs below confirm the small and conflicting effect and exemplify the difficulty.

Chung and Mohidin [3] showed a small (0.23 D) but significant greater rate of progression in a group of 47 children under-corrected by about $0.75 \mathrm{D}$ as compared to another group of 47 children fully corrected for a period of 2 years. They paired the data in an attempt to avoid the problem of intersubject variation. However, the myopia progression rate is very variable, even for paired subjects of the same age and initial refractive error.

Adler and Millodot [4] show no significant myopia progression difference between two groups of 23 fully corrected myopes and 25 myopes under-corrected by $0.50 \mathrm{D}$ for a period of 18 months.

Vasudevan et al. [5] found a significant positive correlation between the degree of under-correction of refractive error and the rate of myopic progression. This result is contradicted by a later study [8]. The difference in myopia progression between the groups with full correction and under-corrected by $0.5 \mathrm{D}$ is less than 0.25D. See its Figure 1 (as amended [9]).

Ong et al. [6] in a longitudinal study concluded that, over a period of at least 3 years, refractive shifts were not significantly different among a group of full-time wearers $(n=8)$ of spectacle correction and a group of non-wearers $(n=5)$, when the data were corrected for age effects. The non-wearers, however, developed less myopia than the fulltime lens wearers, and the difference was borderline significant when there was no "correction" for age effects. The age "correction" may be questionable given the large variation in progression rate and the reduced number of subjects. The natural variation in myopia progression is much larger than the effect of undercorrection.

A recent study of two groups of under-corrected and fully corrected children [8] failed to show any difference in myopia progression. However, the regression analysis showed that 
myopia progression significantly decreased with increasing amount of under-correction. This result supports the feedback model prediction that a sufficient amount of under-correction will noticeably reduce myopia progression.

In the two studies $[3,5]$ showing greater myopia progression when under-corrected versus corrected, we notice that the difference in progression is below the 0.25 -D generally accepted step in refractions and prescriptions, a quantization error. The effect observed is less than the quantization error.

All these studies used different groups of subjects. Rather than comparing the myopia progression in two groups, a better designed study could compare the myopia progression of the same subjects before and after correction (or under-correction). For example, newly diagnosed myopes could be left uncorrected for a period of time, and their rate of myopia progression before and after correction compared.

A study without group assignment showed that fully corrected eyes had a significantly faster myopia progression of $0.36 \mathrm{D} /$ year than the uncorrected or under-corrected fellow eye [10].

In summary, the current literature is inconclusive and contradictory on the issue, but it tends to indicate that undercorrection may be of limited benefit. The feedback model for emmetropization is consistent with most results. It predicts an increased constant progression for fully corrected myopia, and can provide a prediction of what progression to expect depending on the treatment, such as the amount of undercorrection. Those predictions could then be compared to actual refractions. It would be desirable to design future experiments with current knowledge to demonstrate the effect of under-correction or no correction.

The author certifies that he has no affiliations with or involvement in any organization or entity with any financial interest in the subject matter or materials discussed in this manuscript.

\section{References}

1. Galvis V, Tello A, Blanco O, Parra MM (2015) Refractive correction and myopia progression. Graefes Arch Clin Exp Ophthalmol. doi:10.1007/s00417-015-3108-x

2. Medina A (2015) The progression of corrected myopia. Graefes Arch Clin Exp Ophthalmol 253:1273-1277. doi:10.1007/s00417015-2991-5

3. Chung K, Mohidin N (2002) Undercorrection of myopia enhances rather than inhibit myopia progression. Vision Res 42:2555-2559

4. Adler D, Millodot M (2006) The possible effect of undercorrection on myopic progression in children. Clin Exp Optom 89:315-321

5. Vasudevan B, Esposito C, Peterson C, Coronado C, Ciuffreda KJ (2014) Under-correction of human myopia - Is it myopigenic?: A retrospective analysis of clinical refraction data. J Optom 7:147152. doi:10.1016/j.optom.2013.12.007

6. Ong E, Grice K, Held R, Thorn F, Gwiazda J (1999) Effects of spectacle intervention on the progression of myopia in children. Optom Vis Sci 76:363-369

7. Cheng D, Woo GC, Drobe B, Schmid KL (2014) Effect of bifocal and prismatic bifocal spectacles on myopia progression in children: three-year results of a randomized clinical trial. JAMA Ophthalmol 132(3):258-264. doi:10.1001/jamaophthalmol.2013.7623

8. Li SY, Li SM, Zhou YH, Liu LR, Li H, Kang MT, Zhan SY, Wang N, Millodot M (2015) Effect of undercorrection on myopia progression in 12-year-old children. Graefes Arch Clin Exp Ophthalmol. doi:10.1007/s00417-015-3053-8

9. Vasudevan B, Esposito C, Peterson C, Coronado C, Ciuffreda KJ (2014) Erratum to: "Under-correction of human myopia - is it myopigenic?: a retrospective analysis of clinical refraction data" [J Optom 7(3) (2014) 147-152]. J Optom 7:246. doi:10.1016/j.optom. 2014.09.004

10. Phillips J (2005) Monovision slows juvenile myopia progression unilaterally. Br J Ophthalmol 89:1196-1200. doi:10.1136/bjo.2004. 064212 